\title{
Wealth, Wealth Indices and HIV Risk in East Africa
}

For nearly two decades, the conviction that poverty fuels the spread of HIV in Sub-Saharan Africa has been ubiquitous among epidemiologists and development workers. ${ }^{1-3}$ In 2005, however, a team of epidemiologists ${ }^{4}$ published a comment in The Lancet drawing attention to some surprising findings: Demographic and Health Survey (DHS) data from Kenya and Tanzania appear to demonstrate that HIV prevalence is highest among the wealthiest segments of those populations, and lowest among the poor. ${ }^{5,6}$ In light of these findings, the authors suggested that wealth, rather than poverty, may be the root cause of behavioral risk for HIV in Sub-Saharan Africa.

This interpretation of DHS findings depends on the validity of the measurement of wealth. I argue here that the DHS approach to measuring wealth is inconsistent with the complexities of contemporary African livelihoods. As a result, the conclusion that wealth fuels the spread of HIV in East Africa may be misleading.

Neither the Kenyan nor the Tanzanian survey collected direct measurements of individual or household wealth. Rather, both used a recently developed measure called the DHS Wealth Index, which was created by investigators working at ORC Macro, the U.S. firm that collaborates with governments of developing countries to monitor trends in socioeconomic conditions, demographic behavior and health via periodic surveys. ${ }^{7}$ The purpose of the index is to quantify the economic resources of households without directly asking household members about their incomes and expenditures or the total value of their assets. This is a laudable goal. Even in developed countries, where most households have bank accounts and checkbooks and compute their incomes annually for tax purposes, measures of income and wealth based on self-reported data are notoriously unreliable. ${ }^{8}$ The DHS Wealth Index circumvents this problem by using a simple inventory of selected assets for each household; principal components analysis is then applied to summarize this inventory in a single dimension. Other investigators, working independently, have developed similar approaches to quantifying variations in household wealth in developing countries. ${ }^{9}$

Clearly, the index measures something of social significance, as shown by its strong correlation with diverse social and health outcomes. The association with HIV prevalence is but one example. Yet the significance of these DHS findings to an understanding of the socioeconomic forces underlying the HIV epidemics of Sub-Saharan Africa depends on how we interpret the index. If we interpret it as presented-that is, as a measure of wealth-then our dis- cussion may reasonably be limited to how HIV prevalence varies along a unidimensional continuum from extreme poverty to extreme wealth, and how either poverty or wealth, or both, may be implicated in the creation of behavioral risk for HIV.

However, when one considers the profound transformations of Sub-Saharan African economies and ways of life that have occurred over the past two centuries, another interpretation of the DHS Wealth Index and its association with HIV prevalence becomes apparent. Historically, wealth in these social systems has taken a limited number of forms, which varied according to the local ecology and culture..$^{10,11}$ In many places, ownership of cattle was the most important form of wealth. In other areas, the primary form of wealth was the control of human labor through kinship systems. More recently, sustained population growth and increased opportunities for trade led to a shortage of arable land, and thus land itself became an important form of wealth. ${ }^{12}$

As a result of these and other changes, the people of SubSaharan Africa today base their livelihoods on two separate but interdependent sectors of the economy-traditional forms of subsistence production and the growing cash economy. ${ }^{10,13}$ Like the former, the latter takes diverse forms, from cash cropping of coffee and other goods for the global market, to wage labor in the mining and tourism industries or on plantations, to employment in government agencies. Some people rely mainly on traditional forms of subsistenceoriented agricultural production, while others rely more on the cash economy. Most people are members of families that have some stake in both sectors, though the balance varies from family to family, from ethnic group to ethnic group and from place to place.

With these economic and cultural transformations in mind, the DHS Wealth Index takes on an additional interpretation as a measure not only of wealth, but also of involvement in the modern cash economy as opposed to the traditional sector. Most of the assets that are counted in the index are commodities purchased with cash in modern markets-radios, bicycles, telephones and so forth. ${ }^{7}$ Traditional forms of wealth, including cattle, land and the control of human labor through kinship systems, are either not included in the index at all (as in the 1998 Kenya DHS) or constitute a small minority of the indicator variables used to form the index (as in the 1995 Egypt DHS).

Moreover, when traditional forms of wealth are included, it appears that they actually contribute negatively to the index. This is apparent when one considers the proportion
By Jeffrey $B$. Bingenheimer

Jeffrey B.

Bingenheimer is a Robert Wood Johnson Foundation Health \& Society Scholar in the Department of Society, Human Development and Health, Harvard School of Public Health, Harvard University, Boston, MA, USA. 
of households owning certain assets across quintiles of the DHS Wealth Index. For example, in the 1995 Egypt DHS, $43 \%$ of households in the lowest wealth quintile owned land, whereas only $11 \%$ of those in the highest quintile did so. ${ }^{7}$ Similarly, $57 \%$ of households in the lowest quintile owned livestock, compared with only 3\% in the highest quintile. A similar pattern appears in the 1992-1993 India DHS. ${ }^{7}$ In both countries, two of the most important traditional forms of wealth were much more likely to be found in households categorized as poor by the DHS Wealth Index than in those categorized as wealthy. These patterns imply that traditional forms of wealth (when they were included at all) must have received negative weights in the construction of the index. These patterns are quite remarkable for an index that purports to measure household wealth in developing countries.

This leads to a situation in which some people may appear to be wealthy when one considers their traditional holdings, yet appear to be poor according to their score on the DHS Wealth Index. An elderly male, for example, may be economically secure because of land and livestock holdings and his ability to call on children and relatives for labor and other forms of assistance, but he may lack virtually all of the assets included in the index. In contrast, an urban female may have several of the assets included in the index, such as electricity, a telephone and piped water, yet be economically insecure because of her lack of traditional holdings and her isolation from a kinship network. If she loses her job, her only recourse may be to turn to informal sex work to meet her most basic housing and nutritional needs while she searches for another position. Her high score on the DHS Wealth Index may mask her underlying economic insecurity.

This is not to suggest that the DHS Wealth Index does not measure wealth at all. Clearly it does. But by counting certain forms of wealth more than others (and by negatively weighting traditional forms of wealth), the index also measures involvement with the modern, cash-oriented sectors of Sub-Saharan African economies. This interpretation is bolstered by the index's correlation with other socioeconomic variables, such as urbanization and formal education. For example, in the 1998 Kenya DHS, only 1\% of households in the lowest quintile of the DHS Wealth Index were located in urban areas, compared to $67 \%$ of households in the highest quintile. ${ }^{7}$ This gradient was even more pronounced in other countries, including Côte d'Ivoire, Mozambique, Zambia and Zimbabwe. Similarly, the mean number of years of formal education for household heads in the 1998 Kenya DHS ranged from 4.5 years in the lowest quintile of the index to 10.0 years in the highest quintile.

This alternative view of what the DHS Wealth Index actually measures influences the interpretation of the correlations between the index and HIV prevalence in Kenya and Tanzania. Does the positive association mean that wealth itself renders people more vulnerable to HIV? Or does participation in the modern, as opposed to the traditional, sec- tor of the economy render them vulnerable? Perhaps both modern and traditional forms of wealth shield people from behavioral risk for HIV, but the relative degree of their reliance on the modern and traditional sectors influences their risk.

The social forces underlying the epidemics of HIV in SubSaharan Africa are undoubtedly complex and powerful. Clearly, poverty generates circumstances in which some people have few options but to accept a high level of behavioral risk for HIV. ${ }^{14}$ Wealth may also play a role in generating risk for some people. But the complexity of these processes will be obscured if the discourse of epidemiologists and social scientists is constrained by a unidimensional, dehistoricized view of wealth and socioeconomic position. The DHS Wealth Index is a welcome addition to our arsenal of empirical tools, but like all tools, it should be used cautiously and with a full appreciation of its ambiguities and limitations.

\section{REFERENCES}

1. Fenton L, Preventing HIV/AIDS through poverty reduction: the only sustainable solution? Lancet, 2004, 364(9440):1186-1187.

2. Parker RG, Easton D and Klein CH, Structural barriers and facilitators in HIV prevention: a review of international research, AIDS, 2000, 14(Suppl. 1):S22-S32.

3. World Bank, Confronting AIDS: Public Priorities in a Global Epidemic, Oxford, UK: Oxford University Press, 1997.

4. Shelton JD, Cassell MM and Adetunji J, Is poverty or wealth at the root of HIV? Lancet, 2005, 366(9491):1057-1058.

5. Central Bureau of Statistics (CBS), Ministry of Health (MOH) and ORC Macro, Kenya Demographic and Health Survey, 2003, Calverton, MD, USA: CBS, MOH and ORC Macro, 2004

6. Tanzania Commission for AIDS (TACAIDS), National Bureau of Statistics (NBS) and ORC Macro, Tanzania HIV/AIDS Indicator Survey, 2003-2004, Calverton, MD, USA: TACAIDS, NBS and ORC Macro, 2005.

7. Rutstein SO and Johnson K, The DHS Wealth Index, DHS Comparative Reports, Calverton, MD, USA: ORC Macro, 2004, No. 6.

8. Bound J, Brown C and Mathiowetz N, Measurement error in survey data, in: Leamer EE and Heckman JJ, eds., Handbook of Econometrics, Vol. 5, New York: North-Holland, 2001, pp. 3705-3843.

9. Filmer D and Pritchett L, Estimating wealth effects without expenditure data-or tears: an application to educational enrollments in states of India, Demography, 2001, 38(1):115-132.

10. Iliffe J, Africans: The History of a Continent, Cambridge, UK: Cambridge University Press, 1995.

11. Lesthaeghe RJ, Production and reproduction in Sub-Saharan Africa: an overview of organizing principles, in: Lesthaeghe RJ, ed., Reproduction and Social Organization in Sub-Saharan Africa, Berkeley, CA, USA: University of California Press, 1989, pp. 13-59

12. Moore SF, Social Facts and Fabrications: Customary Law on Kilimanjaro, 1880-1980, Cambridge, UK: Cambridge University Press, 1988.

13. Weisner TS, Support for children and the African family crisis, in: Weisner TS, Bradley C and Kilbride PL, eds., African Families and the Crisis of Social Change, Westport, CT, USA: Bergin \& Garvey, 1997, pp. 20-44.

14. Farmer P, Connors M and Simmons J, Women, Poverty, and AIDS: Sex, Drugs and Structural Violence, Monroe, ME, USA: Common Courage Press, 1996

Author contact: jbingenh@hsph.harvard.edu 